\title{
Article \\ Simplified Method of Determining Torsional Stability of the Multi-Storey Reinforced Concrete Buildings
}

\author{
Prashidha Khatiwada * and Elisa Lumantarna
}

Citation: Khatiwada, P.; Lumantarna, E. Simplified Method of Determining Torsional Stability of the Multi-Storey Reinforced Concrete Buildings. CivilEng 2021, 2, 290-308. https:// doi.org/10.3390/civileng2020016

Academic Editors:

Iman Hajirasouliha and

Miguel Azenha

Received: 28 February 2021

Accepted: 6 April 2021

Published: 12 April 2021

Publisher's Note: MDPI stays neutral with regard to jurisdictional claims in published maps and institutional affiliations.

Copyright: (c) 2021 by the authors. Licensee MDPI, Basel, Switzerland. This article is an open access article distributed under the terms and conditions of the Creative Commons Attribution (CC BY) license (https:/ / creativecommons.org/licenses/by/ $4.0 /)$.
Department of Infrastructure Engineering, The University of Melbourne, Parkville, VIC 3010, Australia; elu@unimelb.edu.au

* Correspondence: prashidha.khatiwada@unimelb.edu.au; Tel.: +61-3-9035-5511

\begin{abstract}
This article proposes a simplified method for determining the elastic radius ratio of the multi-storey reinforced concrete building. The elastic radius ratio is the benchmark parameter of the buildings in determining torsional stability during an earthquake. When buildings are torsionally flexible, the torsional component of seismic response amplifies the overall response of the building. Because of the numbers of simplified assumptions such as the adoption of the single-storey model, much of the published articles have a very limited range of application. Quantifying the interaction of different forces in multi-story non-proportional buildings has been the main challenge of these studies. The proposed "shear and bending combination method" solves this by introducing parameters that can determine the relative influence of individual actions. Moreover, the proposed method applies to buildings with all type of structural systems, having asymmetry, and accidental eccentricity. The method is validated through a parametric study consisting of eighty-one building models and using computer analysis. The proposed method and the research findings of this study are useful in determining the torsional stability of the building, in verifying the results of the computer-based analysis, and in optimizing the structural system in the buildings.
\end{abstract}

Keywords: torsion; torsional rigidity; elastic radius ratio; torsional stiffness ratio; shear and flexural translational stiffness; shear and bending torsional stiffness; reinforced concrete building

\section{Introduction}

The torsional stability of the building is considered significant when designing buildings for seismic actions. When buildings are torsionally flexible/unstable, the torsional component of seismic response may contribute significantly to the overall response of the building. The magnitude and disposition of the translational stiffness offered by the lateral load resisting system in the building are used as the inherent means for providing torsional resistance. In this regard, the reinforced concrete multi-storey buildings are generally provided with moment resisting frame (MRF), cantilever shear walls (SW) or core walls, and the dual or combined system for resisting lateral displacement and torsional rotations. In the MRF system, the reinforced concrete beams and columns are joined rigidly and mainly the shear stiffness of the joint provides resistance to the relative translations and rotations of connected member and the whole building. Whereas in the SW system, shear walls or core walls of relatively large flexural stiffness are provided to resist the translational and torsional response of the building. In the dual system, the above two structural arrangements are combined to further increase the resistance to lateral and torsional displacements. Though the combination of MRF and SW system seems easier, the torsional analysis of such multi-storey building structures is difficult compared to the pure MRF and SW systems due to combined shear and bending responses shown by these buildings under the seismic actions. Moment resisting frame deflects predominantly in a shear mode and shear walls deflect predominantly in a bending mode. The interaction between these two modes provided by the multi-storey rigid floors/slabs creates non-uniform interacting forces between these two systems [1]. Therefore, unlike pure MRF and SW buildings and 
single-storey buildings, the torsional response of multi-storey buildings with the dual system is not only governed by the disposition of the elements providing lateral stiffness but also by the interaction between the consisted elements and their dynamic responses [1].

The issues with analysis of the torsional response of the dual system have been recognized as early as in the forties by Chitty [2]. Multiple attempts were made afterwards to generate simpler solutions mainly by considering numbers of simplified assumptions: the seismic load is taken by elements of the SW system and gravity load is taken by the MRF system [3,4], considering responses due to only fundamental mode [5], considering only two-dimensional motion [6], and idealizing multi-storey building into a single-storey model [7-11]. Because of these simplified assumptions, these studies have a very limited range of real application; for example: given that the stiffness parameters of the building can vary from floor to floor, using a single storey model resulted in an inaccurate estimation of these parameters. As the computational power and the development of structural engineering software became more prominent, the more recent studies [12-15] used a multi-storey building model to try to overcome the limitation of the previous studies. However, most of these multi-storey models are based on the assumption of proportionally varying stiffness in the building floors which is only true for pure MRF or pure SW buildings. In the dual system, this assumption is invalid because of the non-uniform ratio of the torsional moment to the translational force at each floor levels. Moreover, the solutions provided by these authors are complex, are of limited applicability, and some lacked validation with the comprehensive analysis.

Despite the limitations, one of the major contributions of these studies is the identification of the major parameters that determine the torsional response of the building. Three parameters: elastic radius ratio also known as torsional stiffness radius ratio $\left(b_{r}\right)$, normalized eccentricity $\left(e_{r}\right)$, and normalized accidental eccentricity $\left(e_{a c c, r}\right)$ are reported in most of these studies as the major torsional parameter of the building. Out of these three parameters, ' $b{ }_{r}$ ' which represents the degree of disposition of the lateral load resisting elements from the center of rigidity (CR), has been used as the benchmark parameter to determine the torsional stability or stiffness of the buildings. In a recent study, Khatiwada et al. [16] also observed that ' $e_{r}$ ' is only influential to the torsional response of low-rise buildings and has small to no impact on medium-rise, and high-rise buildings; whereas, ' $b_{r}$ ' was found to be equally influential in all three types of buildings. Similarly, Lam et al. [17], observed that increasing ' $b_{r}$ ' by less than $10 \%$ has an equal impact on torsional resistance as decreasing ' $e_{r}$ ' by more than $50 \%$. In contrast to stiffness or strength eccentricity, accidental eccentricity which induces dynamic effect is present in the structurally symmetric as well as asymmetric structures [18]. The method proposed in this paper focuses on the fast and accurate manual calculation of the value of ' $b_{r}$ ' by also incorporating the effect of eccentricity $(e)$ and accidental eccentricity $\left(e_{a c c}\right)$.

Mostly, computer analysis requiring multi-step complex procedures are used to determine the accurate value of ' $b_{r}$ '. One of the widely used methods is quantifying ' $b_{r}$ ' by determining the ratio of the uncoupled torsional to translational frequency ratio (also expressed as $\Omega$ by many authors) through dynamic analysis [19-21]. Despite being complex and laborious, this method cannot be used directly for the asymmetrical buildings in which the coupling of the translational and torsional responses is dominant due to the eccentricity. As finding uncoupled frequencies of such buildings is very difficult [21], recently, the authors have developed a more robust "static analysis method (SAM)" also known as "generalized force method" $[16,22]$ applicable for symmetric as well as asymmetric buildings. This method requires a two-step static analysis of the building. Despite having difficulties with complex computer analysis, only a few authors [20,23-25] have published articles in the manual calculation of ' $b_{r}$ ' value. In a more recent study [25], a manual method requiring floor displacement results from computer analysis has been provided. In this study, the displacement of the building at the particular floor levels was used in addition to the details of the building structural system. In [25], an example calculation of the ' $b_{r}$ ' value for the mono-symmetric single-storey pure shear wall building was provided and 
the results were compared with $[23,24]$. From the comparison, all three methods estimated different values of ' $b_{r}$ ', with [24,25] predicting $b_{r}<1$, while [23] predicted $b_{r}>1$. This ambiguity is mainly due to different authors using different simplifying assumptions such as only considering pure shear wall or pure frame system, adopting a single storey model, and ignoring the torsional contribution of the individual walls. These methods also lacked proper validation and their application is questionable. Therefore, the main objective of this study is to resolve these issues by providing a fast, simple, and reliable method for determining ' $b_{r}$ ' and the torsional stability of the building.

In this paper, the proposed "shear and bending combination method (SBCM)" method is validated through calculation of ' $b_{r}$ ' value in the 81 building models (consisting of pure SW, pure MRF, and dual system, and buildings with heights in the range of $10 \mathrm{~m}$ to $115 \mathrm{~m}$ ) and comparing the results with the "static analysis method (SAM)". Furthermore, a parametric study is undertaken to find out the effects of several parameters in the ' $b_{r}$ ' value such as disposition of the structural elements in the building plan, the magnitude of lateral stiffness, flexural to shear lateral stiffness ratio (in the dual system), building aspect ratio, building height, eccentricity, and accidental eccentricity. The extensive and successful validation of the proposed SBCM method proves that it can be reliably used for determining torsional stability of the building, for verifying the results of the computerbased analysis, and in applying the research findings to optimizing structural elements during seismic design.

\section{Methods and Procedures of Determining Elastic Radius Ratio $\left(b_{r}\right)$}

Two methods and their procedures for determining the elastic radius ratio $\left(b_{r}\right)$ are presented in this paper. The first method which is the shear and bending combination method (SBCM) is proposed in this paper to manually calculate the ' $b_{r}$ ' value. The second method, known as the static analysis method (SAM), has been developed by the authors in $[16,22]$ and is used for the verification of the proposed method. These methods are discussed in details in the following sections.

\subsection{Shear and Bending Combination Method (SBCM)}

The SBCM is proposed in this study to facilitate the easy and fast estimation of the elastic radius ratio $\left(b_{r}\right)$ of buildings consisting of a pure moment resisting frame (MRF), pure shear wall (SW), and dual or combined structural system. The proposed method is derived based on the assumption that the torsional stiffness in the RC building is provided mainly through shear and bending mechanisms. The procedure of the proposed "SBCM" method is shown by a flowchart in Figure 1.

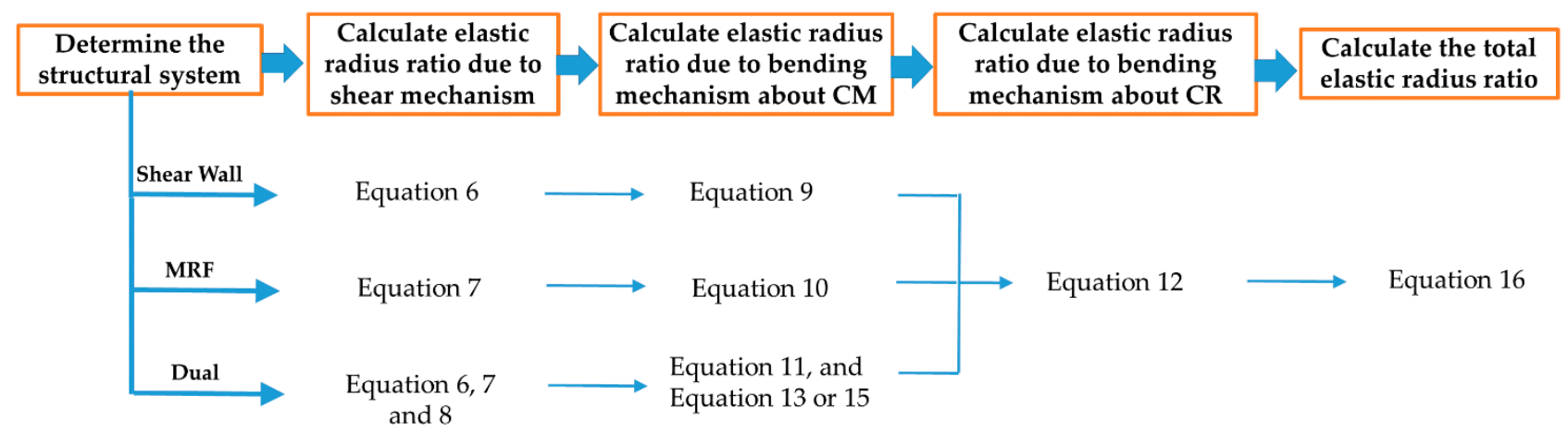

Figure 1. The procedure of determining the elastic radius ratio by the proposed shear and bending combination method (SBCM) method.

The shear mechanism is developed due to an individual shear wall trying to resist torsional moment acting about its vertical axis as shown in Figure 2. As this mechanism 
develops within the structural members, the elastic radius ratio due to this mechanism does not depend on the value of eccentricities.

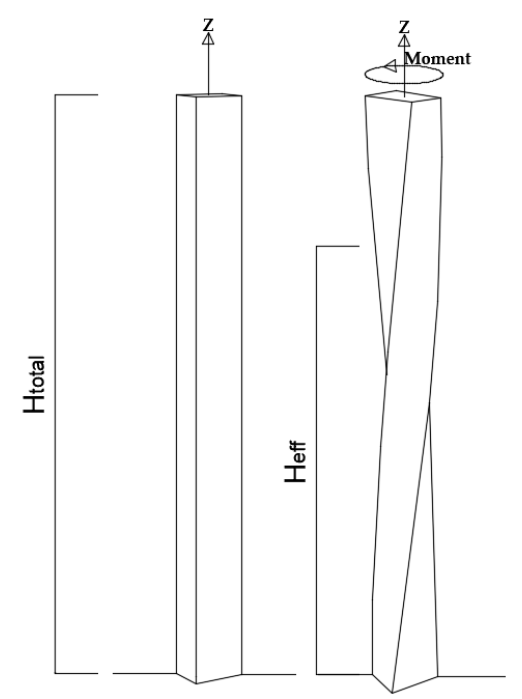

Figure 2. Development of torsional stiffness due to the shear mechanism.

The elastic torsional radius due to shear mechanism $\left(b_{s}\right)$ can be determined from the square root of the sum of the ratio of torsional stiffness $\left(K_{\theta}\right)$ to translational stiffness $(K)$ of each wall or column in the building as shown in Equation (1). In Equation (1), ' $b_{y, s}$ ' is the torsional stiffness radius due to the shear mechanism developed for $y$-direction of ground motion, and $K_{x, i}$ is the translational stiffness of element ' $i$ ' about the x-axis.

$$
b_{y, S}=\sqrt{\sum_{i=1}^{n} \frac{K_{\theta, s i}}{K_{x, i}}}
$$

The elastic radius ratio due to the shear mechanism $\left(b_{r s}\right)$ can be determined by dividing Equation (1) with the mass radius of gyration of the floor plan of the building. The mass radius of gyration is equal to $\sqrt{\frac{L_{x}^{2}+L_{y}^{2}}{12}}$ for rectangular buildings with lengths ' $L_{x}$ ' and ' $L_{y}$ ', and for other regular and irregular shaped building it can be determined using the coordinate method provided in [26].

$$
b_{r y, S}=\frac{b_{y, S}}{r}=\frac{1}{r} \sqrt{\sum_{i=1}^{n} \frac{K_{\theta, s i}}{K_{x, i}}}
$$

For each wall or column ' $i$ ' with uniform cross-section about its height, the torsional stiffness due to shear $\left(K_{\theta, s i}\right)$ can be determined from shear modulus $(G)$, torsion constant $(J)$ and effective height $\left(H_{\text {eff }}\right)$ as shown in Equation (3). Similarly, the translational stiffness $\left(K_{i}\right)$ for $y$-direction of motion can be determined from Equation (4) based on Young's modulus $(E)$, second moment of area $(I)$, effective height $\left(H_{\text {eff }}\right.$ ), and stiffness factor ' $\alpha$ ' (equal to 3 for cantilever wall and 12 for columns restrained by building floors). In Equation (3), the shear modulus $(G)$ is interchanged with ' $E / 2(1+v)^{\prime}$. ' $v$ ' is the Poisson's ratio.

$$
\begin{gathered}
K_{\theta, s i}=\frac{G_{i} J_{i}}{H_{e f f, i}}=\frac{E_{i} J_{i}}{2\left(1+v_{i}\right) H_{e f f, i}} \\
K_{x, i}=\frac{\alpha E_{i} I_{x, i}}{H_{e f f, i}{ }^{3}}
\end{gathered}
$$

The effective height $\left(H_{\text {eff }}\right)$ of walls and columns are determined from Table 1. 
Table 1. Effective height ' $H_{\text {eff' }}$ in term of the total height of building ' $H$ ' and storey height ' $h$ '.

\begin{tabular}{cc}
\hline Conditions & $\boldsymbol{H}_{\text {eff }}$ \\
\hline Walls in pure SW system & $1+0.77 \mathrm{H}$ \\
\hline Walls in dual system & $3.1 H^{0.5} / \log (H)$ \\
\hline Columns & $h$ \\
\hline
\end{tabular}

Combining Equations (2)-(4) gives,

$$
b_{r y, S}=\frac{1}{r} \sqrt{\sum_{i=1}^{n} \frac{H_{e f f, i}{ }^{2}}{2 \alpha\left(1+v_{i}\right)} \frac{J_{i}}{I_{x, i}}}
$$

Equation (5) can be separated into Equations (6) and (7) for walls and columns, respectively. The elastic radius ratio due to shear mechanism in wall ' $b_{r y, s w}$ ' and columns ' $b_{r y, S c}$ ' can then be combined using Equation (8). ' $b_{r y, S}$ ' determined from Equations (5) and (8) will give the same result.

$$
\begin{gathered}
b_{r y, S w}=\frac{1}{r} \sqrt{\sum_{i=1}^{n_{w}} \frac{H_{e f f, i}{ }^{2}}{6\left(1+v_{i}\right)} \frac{J_{i}}{I_{w x, i}}} \\
b_{r y, S c}=\frac{h}{r} \sqrt{\sum_{i=1}^{n_{c}} \frac{1}{24\left(1+v_{i}\right)} \frac{J_{i}}{I_{c x, i}}} \\
b_{r y, S}=\sqrt{b_{r y, S w}^{2}+b_{r y, S c}^{2}}
\end{gathered}
$$

where, ' $n_{w}$ ' and ' $n_{c}$ ' is the number of walls and columns in the building, and ' $I_{w x, i}$ ' and $I_{c x, i}$ ' is the second moment of area of the wall ' $i$ ' and column ' $i$ ' about the x-axis, respectively.

Compared to the shear mechanism, the bending mechanism occurs as a result of the warping or differential bending of the moment resisting frame or shear walls. The ' $b_{r}$ ' value due to bending can be calculated initially about the CM as shown in Equations (9)-(11) for building with SW, MRF and dual system, respectively. This value can be transformed into the CR by subtracting the square of the normalized eccentricity $\left(e_{r}=e / r\right)$ as shown in Equation (12). In Equation (12), the ' $1+e^{2} a c c, r$ ' is introduced to allow for the effect of accidental eccentricity. The derivation of Equation (12) is presented in Appendix A. Equations (9)-(12) presented below represents the equations for the y-direction of earthquake motion and a similar set of equations can be derived for the x-direction of motion. In the equations, ' $k_{w, x}$ ' and ' $k_{f, x}=G A / H_{e f f}$ ' are the translational stiffness of the SW and MRF system, ' $x_{i}$ ' and ' $y_{i}$ ' are the $x$ and $y$-coordinates of individual structural elements with respect to $\mathrm{CM}$ of the building as presented in Figure 3 , and ' $P_{x}$ ' is the stiffness ratio determined from Equations (13) and (14).

For pure SW system,

$$
b_{r y, B, C M}^{2}=b_{r y, w}^{2}=\frac{\sum K_{w, y i} y_{i}{ }^{2}+\sum K_{w, x i} x_{i}^{2}}{r^{2} \sum K_{w, x i}}=\frac{\sum I_{w, y i} y_{i}{ }^{2}+\sum I_{w, x i} x_{i}{ }^{2}}{r^{2} \sum I_{w, x i}}
$$

For pure MRF system,

$$
b_{r y, B, C M}^{2}=b_{r y, f}^{2}=\frac{\sum K_{f, y i} y_{i}^{2}+\sum K_{f, x i} x_{i}^{2}}{r^{2} \sum K_{f, x i}}=\frac{\sum G A_{y i} y^{2}+\sum G A_{, x i} x_{i}^{2}}{r^{2} \sum G A_{x i}}
$$


For dual system,

$$
\begin{aligned}
b_{r y, B, C M}^{2}=\frac{K_{w, x} b_{r y, w}^{2}+K_{f, x} b_{r y, f}^{2}}{\left(K_{w, x}+K_{f, x}\right)} & =\frac{b_{r y, w}^{2} \times \frac{K_{v, x}}{K_{f, x}}+b_{r y, f}^{2}}{1+\frac{K_{w, x}}{K_{f, x}}}=\frac{b_{r y, w}^{2} \times P_{x}+b_{r y, f}^{2}}{1+P_{x}} \\
b_{r y, B} & =\sqrt{\frac{b_{r y, B, C M}^{2}-e_{r y}^{2}}{1+e_{a c c, r y}^{2}}}
\end{aligned}
$$
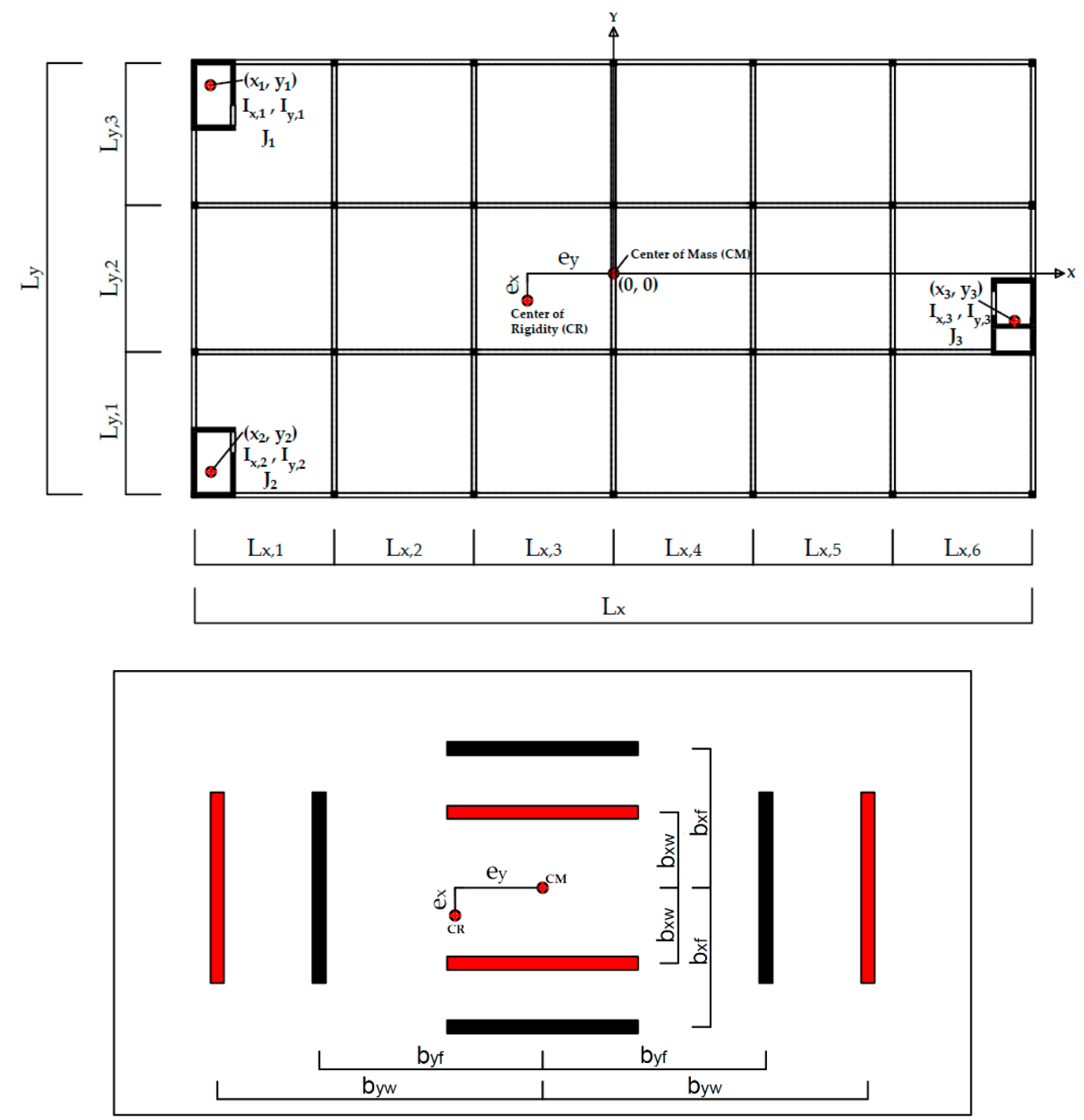

Figure 3. Dual system and the equivalent idealized pairs providing torsional stiffness through bending. (a) A dual system with structural details showing the disposition of frames and shear walls. (b) Dual system idealized into pairs of pure SW system (red) and pure moment resisting frame (MRF) system (black) in each direction showing the distances of the idealized elements from the center of mass (CM).

$$
P_{x}=\frac{K_{w, x}}{K_{f, x}}=\frac{\sum_{i=1}^{n_{w}} \frac{3 E_{i} I_{w x, i}}{H_{e f f, i}{ }^{3}}}{\sum_{i=1}^{n_{c}} \frac{G A_{x, i}}{H_{e f f, i}}}=\frac{\sum_{i=1}^{n_{w}} \frac{3 E_{i} I_{w x, i}}{H_{e f f, i}{ }^{3}}}{\sum_{i=1}^{n_{c}} \frac{12 E_{i} I_{c x, i}}{\lambda_{i, x} h^{2} H_{e f f, i}}}=\frac{\sum_{i=1}^{n_{w}} \frac{E_{i} I_{w x, i}}{(1+0.67 H)^{2}}}{\sum_{i=1}^{n_{c}} \frac{4 E_{i} I_{c x, i}}{\lambda_{i, x} h^{2}}}
$$




$$
\lambda_{i, x}=1+\frac{\frac{2 I_{c x_{i}}}{h}}{\frac{I_{b x, i 1}}{l_{y, i 1}}+\frac{I_{b x, i 2}}{l_{y, i 2}}}
$$

where, ' $I_{c x, i}$ ' is the second moment of area of column ' $i$ '. Similarly, ' $I_{b x, i 1}$ ' and ' $I_{b x, i 2}$ ', and ' $l_{y, i 1}$ ' and ' $l_{y, i 2}$ ' are the second moment of areas and lengths of the beams connected to the columns, respectively. Moreover, the effective height $\left(H_{\text {eff }}\right)$ is determined from the total height of the building $(H)$ and is equal to ' $1+0.67 H^{\prime}$.

For a symmetrical frame system having uniform size and material properties for all columns and all beams, Equation (13) can be simplified into Equation (15).

$$
P_{x}=\left(1+\frac{I_{c x}}{I_{b x}} \frac{l}{h}\right) \frac{h^{2}}{4(1+0.67 H)^{2}} \frac{\sum I_{w x}}{n_{c} I_{c x}}
$$

Finally, the total elastic radius ratio $\left(b_{r}\right)$ about the CR of the building is determined by combining the shear component ' $b_{r, S}$ ' (Equation (8)) and the bending component ' $b_{r, B}$ ' (Equation (12)) by the square root of the sum of the square method given in Equation (16).

$$
b_{r y}=\sqrt{b_{r y, S}^{2}+b_{r y, B}^{2}}
$$

\subsection{Static Analysis Method (SAM)}

The static analysis method (SAM) is the robust method of determining elastic radius ratio ' $b_{r}$ ' based on the static analysis of the building performed in the computer. The method has been developed by the authors in [16,22], and the procedure is summarized below.

a. Determining the effective value of pure translational displacement $\left(\Delta_{2 D}\right)$ by applying a lateral load at an arbitrary location to the building that is restrained for torsional rotation,

b. Determining the effective edge displacements: flexible edge displacement $\left(\Delta_{\max }\right)$, and stiff edge displacements $\left(\Delta_{\min }\right)$ for the same lateral load and location without the torsional restraints,

c. Determining the position of the center of rigidity (CR). CR from a stiff edge is equal to $\frac{\left(\Delta_{2 D}-\Delta_{\min }\right) \cdot L}{\Delta_{\max }-\Delta_{\min }}$,

d. Determining the distance between the applied load and the CR. The distance is equal to the sum of eccentricity $(e)$ and accidental eccentricity $\left(e_{a c c}\right)$. The accidental eccentricity such as $0.05 \mathrm{~L}$ or $0.1 \mathrm{~L}$ is adopted from the relevant seismic codes.

e. The elastic radius ratio $\left(b_{r}\right)$ is finally determined by substituting the above parameters in Equation (17).

$$
b_{r}=\frac{1}{r} \sqrt{\frac{\Delta_{2 D} \cdot\left(e+e_{a c c}\right) \cdot L}{\Delta_{\max }-\Delta_{\min }}}
$$

\subsection{Parametric Study}

The proposed (SBCM) was used to determine the elastic radius ratio $\left(b_{r}\right)$ of the ten basic symmetrical $(e=0)$ building models as shown in Figures 4 and 5 , and three real asymmetric buildings as shown in Figure 6 . The results were verified with the ' $b_{r}$ ' value calculated using the SAM. The details of the structural systems: frames and shear walls are provided in Figure 5 for the symmetrical models, and Figure 6 for the asymmetrical models. The symmetrical models have building dimensions of $24.7 \mathrm{~m} \times 24.7 \mathrm{~m}$, the radius of gyration $(r)$ of $10.08 \mathrm{~m}$, and a typical floor height of $3.1 \mathrm{~m}$. Similarly, the column and beam sizes of these models are $350 \mathrm{~mm} \times 350 \mathrm{~mm}$, and $500 \mathrm{~mm} \times 250 \mathrm{~mm}$, respectively. The asymmetric building models have normalized eccentricity $\left(e_{r}\right)$ in the range of 0.01 to 0.28 , and $10 \%$ accidental eccentricity. 


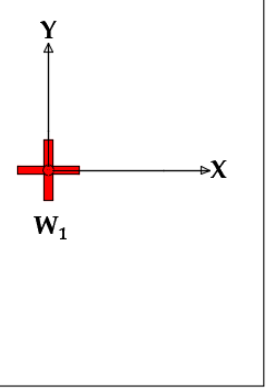

(a) Model 'a' (cross wall at the center)

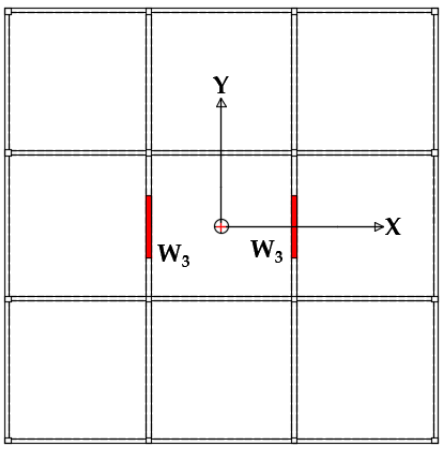

(d) Model 'd' (MRF + 2 parallel walls)

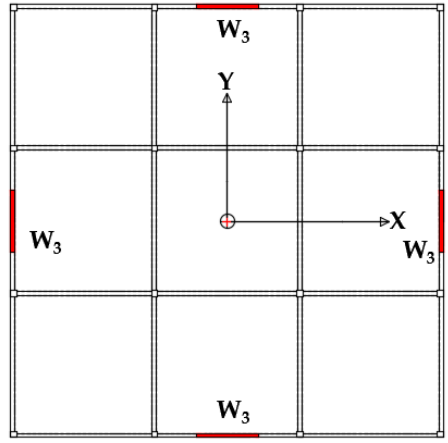

(g) Model 'g' (MRF + 4 edge walls)

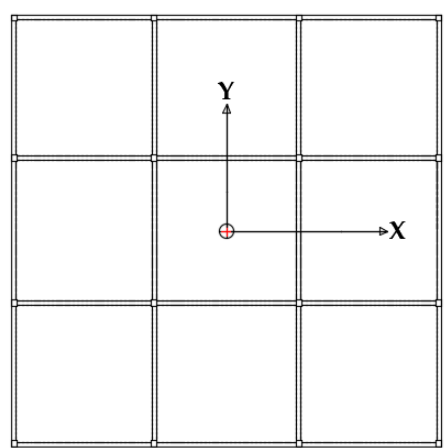

(b) Model 'b' (pure MRF)

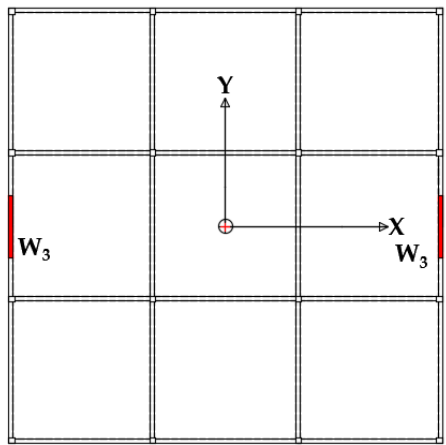

(e) Model 'e' (MRF + 2 edge walls)

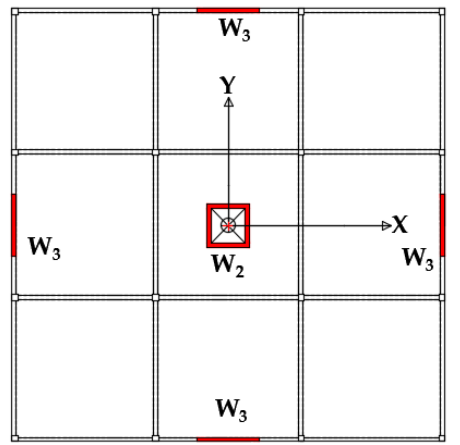

h) Model 'h' (MRF + 4 edge walls + core)

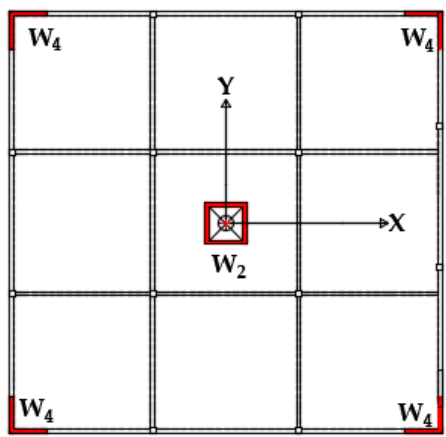

(j) Model 'j' (MRF + 4 corner walls + core)

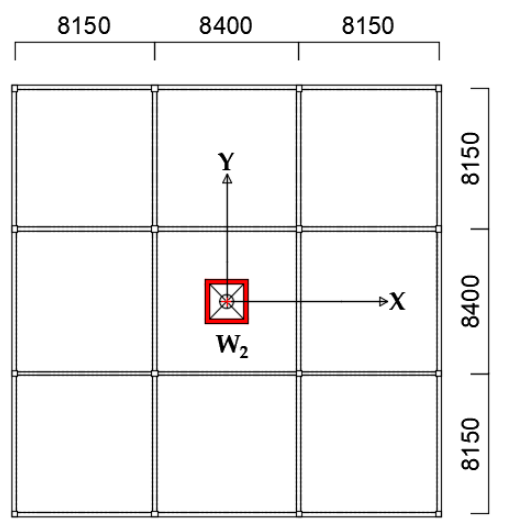

(c) Model 'c' (MRF + central core)

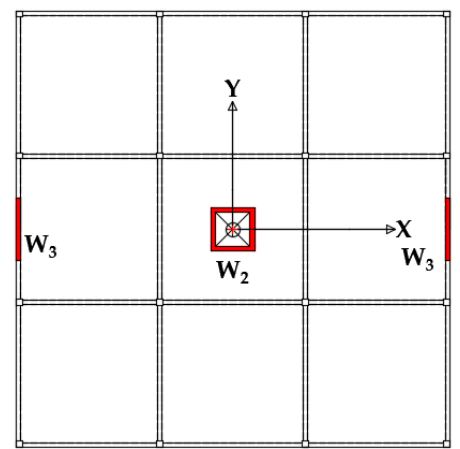

(f) Model ' $\mathrm{f}$ ' (MRF + 2 edge walls + core)

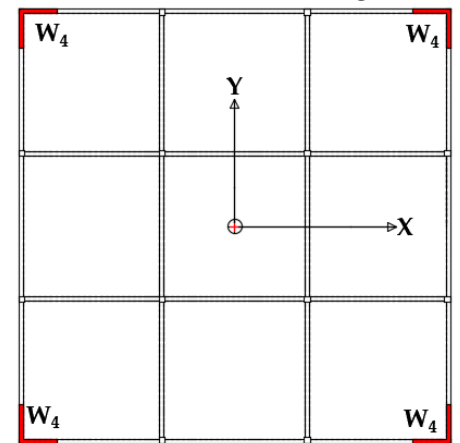

(i) Model 'i' (MRF + 4 corner walls)

Figure 4. Floor plan and structural details of the symmetrical building models ' $a$ ' to ' $j$ ' used for the parametric study. The building dimensions of all the models are the same as the building dimensions provided for building model ' $c$ '. 


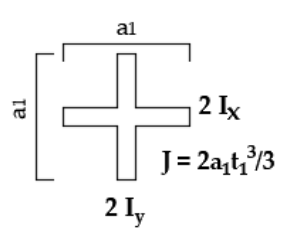

$W_{1}$ (thickness, $\left.t_{1}=2 t\right)$

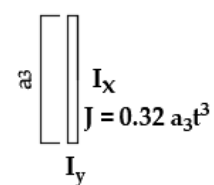

$\mathrm{W}_{3}$ (thickness $=\mathrm{t}=0.07 \mathrm{a}_{3}$

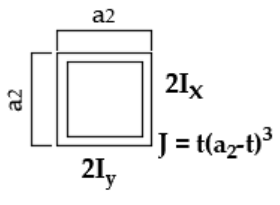

$W_{2}($ thickness $=t)$

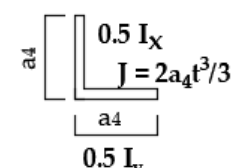

$\mathrm{W}_{4}($ thickness $=\mathrm{t})$

Figure 5. Structural details of the shear walls used in building models Figure $4 \mathrm{a}-\mathrm{j}$.

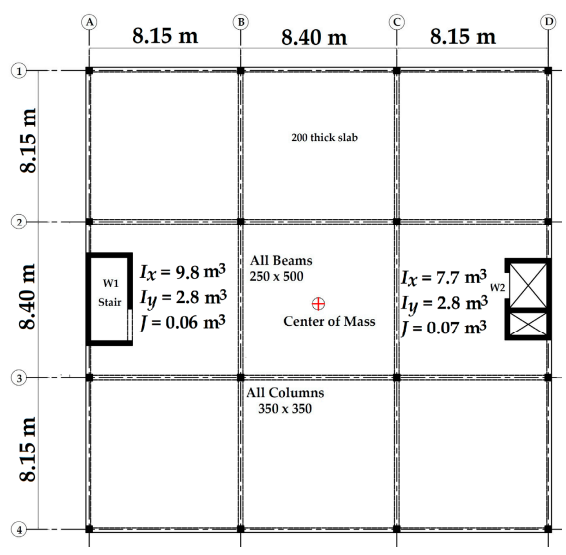

(a)

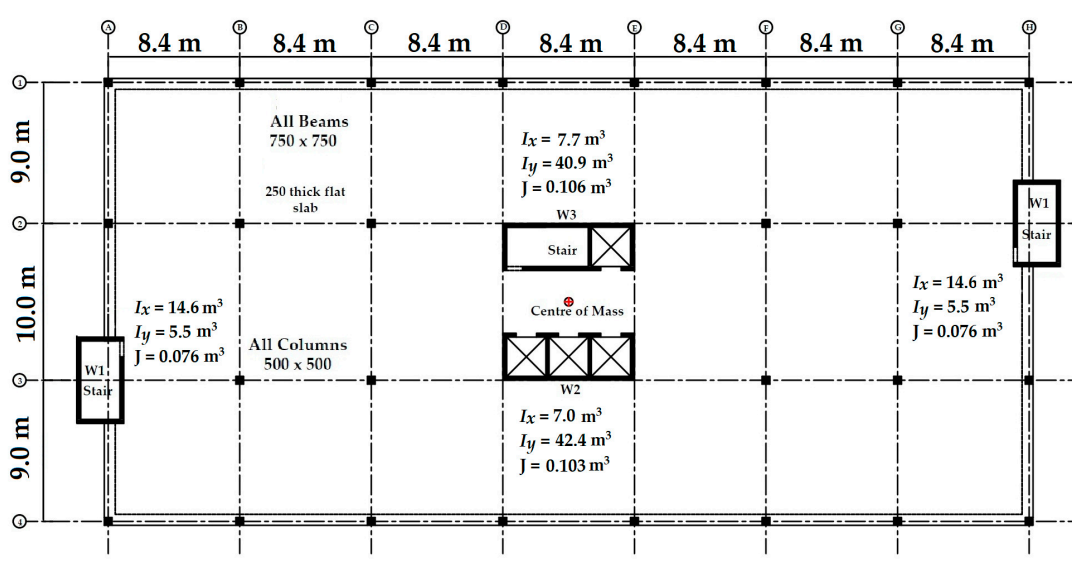

(b)

(c)

Figure 6. Structural details of the asymmetrical buildings: (a) Model 'k' [16], (b) Model '1' [27], and (c) model 'm' [16]. 


\section{Results and Discussion}

The SBCM as introduced in this paper, for the calculation of elastic radius ratio $\left(b_{r}\right)$, has been verified by the comparison of the results obtained from the static analysis method (SAM). Static analysis was performed using a commercial structural engineering software SPACE GASS (Version 12.85, SPACE GASS) [28] by applying the horizontal equivalent static design forces calculated as per current code provisions for seismic actions in Australia [29]. 500 -year return period earthquake with seismic hazard factor $\left(K_{p}\right)$ of $0.08^{\prime} \mathrm{g}$ and site class ' $D_{\mathrm{e}}$ ' were used. Fifty-seven building models (three sets of eighteen symmetric, and one set of three asymmetric building models) were used for the verification purpose. Ten symmetrical building models ' $a$ ' to ' $j$ ', eight equivalent pure shear wall (SW) models of models ' $c$ ' to ' $j$ ' as shown in Figure 4 , and three asymmetrical building models as shown in Figure 6 were used. The three sets of each of these models consisted: 4-storey (13.1 $\mathrm{m}$ height), 10-storey (31.7 $\mathrm{m}$ height), and 37 storeys (115.4 $\mathrm{m}$ height) buildings. Further 24 models (modification of model ' $a$ ' to ' $j$ ') were analyzed to see the changes in ' $b_{r}$ ' value due to changes in the disposition of the structural elements in the building plan, the magnitude of lateral stiffness, flexural to shear lateral stiffness ratio (in the dual system), building aspect ratio, building height, eccentricity, and accidental eccentricity. Example calculations using the proposed "SBCM" method and comparison of the result with "SAM" method, and another manual calculation method [25] for models ' $a$ ' and ' $b$ ' are presented in this section. The example calculation for model ' $\mathrm{g}$ ' is presented in Table A1, and for model ' $k$ ' is presented in Table A2. The results for dual system models ' $c$ ' to ' $j$ ' are summarized in Table 2, for SW equivalent models ' $c$ ' to ' $j$ ' are summarized in Table 3 , and models ' $k$ ' to ' $m$ ' are summarized in Table 4.

- Model 'a' building (pure SW system):

Wall dimension is $a_{1}=3566.3 \mathrm{~mm}$ and $t_{1}=500 \mathrm{~mm}$. From Figure $5,2 I_{x}=2 I_{y}=1.922 \mathrm{~m}^{3}$ and $J=0.297 \mathrm{~m}^{3}$.

For pure SW system with wall at $\mathrm{CR}, b_{r y, B}=b_{r y, B, C M}=b_{r y, w}=b_{r y, f}=0$.

$\mathrm{H}=13.1 \mathrm{~m}$ :

From Equation (6),

$$
b_{r y, S w}=\frac{1}{r} \sqrt{\sum_{i=1}^{n_{w}} \frac{H_{e f f, i^{2}}}{6\left(1+v_{i}\right)} \frac{J_{i}}{I_{w x, i}}}=\frac{1}{10.08} \sqrt{\frac{(1+0.77 \cdot 13.1)^{2}}{6(1+0.2)} \frac{0.297}{1.922}}=0.161 .
$$

And from Equation (16), $b_{r y}=\sqrt{b_{r y, S}^{2}+b_{r y, B}^{2}}=b_{r y, S}=0.161<1$ (the building is torsionally unstable/flexible).

As ' $b_{r y}$ ' from SAM is 0.158 , the absolute percentage difference is $1.9 \%$.

$\mathrm{H}=31.7 \mathrm{~m}$ :

$$
b_{r y}=b_{r y, S w}=\frac{H_{e f f}}{r} \sqrt{\frac{1}{6\left(1+v_{i}\right)} \frac{J_{i}}{I_{w x, i}}}=\frac{(1+0.77 \cdot 31.7)}{10.08} \sqrt{\frac{1}{6(1+0.2)} \frac{0.297}{1.922}}=0.369 .
$$

' $b_{r y}$ ' from 'SAM' is also 0.369 . As $b_{r y}<1$, the building is torsionally unstable/flexible. $\mathrm{H}=115.4 \mathrm{~m}$ :

$$
\left.b_{r y}=b_{r y, S w}=\frac{(1+0.77 \cdot 115.4)}{(1+0.77 \cdot 31.7)} \cdot 0.369=1.306>1 \text { (torsionally stiff }\right) .
$$

' $b_{r y}$ ' from the 'SAM' is also equal to 1.306 . Whereas, as per [25], ' $b_{r y}=0$ ' for all three building heights.

- Model ' $b$ ' building (pure MRF system):

$$
I_{c x}=0.00125 \mathrm{~m}^{4} \text {, and } J=0.141 b d^{3}=0.00212 \mathrm{~m}^{3} .
$$


From Equation (7),

$$
b_{r y, S c}=\frac{h}{r} \sqrt{\sum_{i=1}^{n_{c}} \frac{1}{24\left(1+v_{i}\right)} \frac{J_{i}}{I_{c x, i}}}=\frac{3.1}{10.08} \sqrt{\frac{16}{24(1+0.2)} \frac{0.00212}{0.00125}}=0.3 .
$$

and, for the pure MRF system, from Equation (10),

$$
b_{r y, B}^{2}=b_{r y, f}^{2}=\frac{\sum G A_{y i} y^{2}+\sum G A_{, x i} x_{i}^{2}}{r^{2} \sum G A_{x i}}=\frac{2 G A\left(12.35^{2}+4.2^{2}\right)+2 G A\left(12.35^{2}+4.2^{2}\right)}{4 G A \cdot 10.08^{2}}=1.68 .
$$

From Equation (16), $b_{r y}=\sqrt{b_{r y, S c}^{2}+b_{r y, B}^{2}}=\sqrt{0.3^{2}+1.68}=1.33>1$ (the building is torsionally stiff).

As all variable of $b_{r y}$ of the pure MRF building is height independent, for all three heights: $\mathrm{H}=13.1 \mathrm{~m}, 31.7 \mathrm{~m}$, and $115.4 \mathrm{~m}, b_{r y}=1.33$. From 'SAM', $b_{r y}=1.32$ and the absolute percentage difference is $0.75 \%$. Similarly, based on [25], $b_{r y}=1.39$.

From the above extensive parametric study of the 81 multi-storey building models, it is found that the proposed SBCM can reliably predict the value of the elastic radius ratio ' $b_{r}$ ' for buildings with all three structural types and range of building heights. The proposed method predicted the ' $b_{r}$ ' value within the difference of $5 \%$ compared to the SAM. As the method is highly accurate, it can be used reliably for verifying the results of the computer-based analysis as well as for the seismic design of the buildings. The results also validate the author's initial assumptions that are presented in Section 2.1. The effects of disposition of the lateral load resisting elements, the magnitude of the lateral stiffness, aspect ratio, building height, and eccentricities in ' $b_{r}$ ' value are discussed below.

Table 2. Summary of the ' $b_{r y}$ ' value of the dual system models, calculated from the proposed "Shear and Bending Combination Method (SBCM)" and comparison with the results from the "Static

\begin{tabular}{|c|c|c|c|c|c|c|c|c|}
\hline Models ${ }^{1}$ & $b_{r y, s}$ & $b_{r y, w}$ & $\boldsymbol{b}_{r y, f}$ & $P_{x}$ & $b_{r y, B}$ & $b_{r y}(\mathrm{SBCM})$ & $b_{r y}(\mathrm{SAM})$ & $\%$ Difference \\
\hline$c^{13.1}$ & 0.45 & 0.00 & 1.29 & 5.53 & 0.51 & 0.68 & 0.70 & 3.43 \\
\hline $\mathrm{d}^{13.1}$ & 0.31 & 0.42 & 0.73 & 5.38 & 0.48 & 0.57 & 0.60 & 4.64 \\
\hline $\mathrm{e}^{13.1}$ & 0.07 & 1.23 & 1.25 & 5.38 & 1.23 & 1.23 & 1.24 & 0.35 \\
\hline $\mathrm{f}^{13.1}$ & 0.54 & 0.87 & 1.25 & 10.77 & 0.91 & 1.06 & 1.06 & 0.72 \\
\hline $\mathrm{g}^{13.1}$ & 0.31 & 1.73 & 1.57 & 4.30 & 1.70 & 1.73 & 1.70 & 1.8 \\
\hline$h^{13.1}$ & 0.55 & 1.23 & 1.57 & 9.01 & 1.26 & 1.38 & 1.41 & 2.47 \\
\hline $\mathrm{i}^{13.1}$ & 0.37 & 1.68 & 1.40 & 4.94 & 1.63 & 1.68 & 1.65 & 1.25 \\
\hline $\mathrm{j}^{13.1}$ & 0.58 & 1.23 & 1.40 & 9.85 & 1.24 & 1.37 & 1.39 & 1.49 \\
\hline$c^{31.7}$ & 0.53 & 0.00 & 1.29 & 1.06 & 0.90 & 1.04 & 1.08 & 2.97 \\
\hline $\mathrm{d}^{31.7}$ & 0.31 & 0.42 & 0.73 & 1.03 & 0.59 & 0.67 & 0.66 & 0.38 \\
\hline $\mathrm{e}^{31.7}$ & 0.08 & 1.23 & 1.25 & 1.03 & 1.24 & 1.24 & 1.24 & 0.13 \\
\hline $\mathrm{f}^{31.7}$ & 0.61 & 0.87 & 1.25 & 2.06 & 1.01 & 1.18 & 1.21 & 2.74 \\
\hline $\mathrm{g}^{31.7}$ & 0.32 & 1.73 & 1.57 & 0.8 & 1.64 & 1.67 & 1.65 & 1.2 \\
\hline $\mathrm{h}^{31.7}$ & 0.62 & 1.23 & 1.57 & 1.73 & 1.36 & 1.50 & 1.56 & 4.06 \\
\hline $\mathrm{i}^{31.7}$ & 0.40 & 1.68 & 1.40 & 0.95 & 1.54 & 1.59 & 1.56 & 2.07 \\
\hline $\mathrm{j}^{31.7}$ & 0.66 & 1.23 & 1.40 & 1.89 & 1.29 & 1.45 & 1.52 & 4.63 \\
\hline$c^{115.4}$ & 0.73 & 0.00 & 1.29 & 0.09 & 1.24 & 1.44 & 1.52 & 5.23 \\
\hline $\mathrm{d}^{115.4}$ & 0.32 & 0.42 & 0.73 & 0.08 & 0.71 & 0.78 & 0.74 & 4.84 \\
\hline $\mathrm{e}^{115.4}$ & 0.12 & 1.23 & 1.25 & 0.08 & 1.25 & 1.26 & 1.24 & 1.00 \\
\hline $\mathrm{f}^{115.4}$ & 0.79 & 0.87 & 1.25 & 0.17 & 1.21 & 1.44 & 1.38 & 0.61 \\
\hline $\mathrm{g}^{115.4}$ & 0.34 & 1.73 & 1.57 & 0.06 & 1.58 & 1.62 & 1.63 & 1.8 \\
\hline $\mathrm{h}^{115.4}$ & 0.80 & 1.23 & 1.57 & 0.14 & 1.53 & 1.73 & 1.68 & 3.10 \\
\hline $\mathrm{i}^{115.4}$ & 0.47 & 1.68 & 1.40 & 0.08 & 1.42 & 1.50 & 1.49 & 0.58 \\
\hline $\mathrm{j}^{115.4}$ & 0.86 & 1.23 & 1.40 & 0.15 & 1.38 & 1.63 & 1.64 & 0.96 \\
\hline
\end{tabular}
Analysis Method (SAM)".

${ }^{1}$ The superscript to the model names represents the total building height in meter. 
Table 3. Summary of the ' $b_{r y}$ ' value of the pure shear wall (SW) models, calculated from the proposed shear and bending combination method (SBCM) and comparison with the results from the static analysis method (SAM).

\begin{tabular}{|c|c|c|c|c|c|}
\hline Models & $b_{r y, s}$ & $b_{r y, w}$ & $b_{r y}(\mathrm{SBCM})$ & $b_{r y}(\mathrm{SAM})$ & $\%$ Difference \\
\hline$c^{13.1}$ & 0.50 & 0.00 & 0.50 & 0.50 & 0.79 \\
\hline $\mathrm{d}^{13.1}$ & 0.07 & 0.42 & 0.42 & 0.42 & 0.00 \\
\hline $\mathrm{e}^{13.1}$ & 0.07 & 1.23 & 1.23 & 1.23 & 0.09 \\
\hline $\mathrm{f}^{13.1}$ & 0.45 & 0.87 & 0.97 & 0.97 & 0.17 \\
\hline $\mathrm{g}^{13.1}$ & 0.10 & 1.73 & 1.74 & 1.73 & 0.28 \\
\hline $\mathrm{h}^{13.1}$ & 0.45 & 1.23 & 1.31 & 1.30 & 0.19 \\
\hline $\mathrm{i}^{13.1}$ & 0.15 & 1.73 & 1.74 & 1.74 & 0.14 \\
\hline $\mathrm{j}^{13.1}$ & 0.46 & 1.23 & 1.31 & 1.33 & 1.72 \\
\hline$c^{31.7}$ & 1.14 & 0.00 & 1.14 & 1.14 & 0.34 \\
\hline $\mathrm{d}^{31.7}$ & 0.16 & 0.42 & 0.45 & 0.44 & 0.37 \\
\hline $\mathrm{e}^{31.7}$ & 0.16 & 1.23 & 1.24 & 1.24 & 0.09 \\
\hline $\mathrm{f}^{31.7}$ & 1.01 & 0.87 & 1.33 & 1.36 & 1.69 \\
\hline $\mathrm{g}^{31.7}$ & 0.22 & 1.73 & 1.75 & 1.74 & 0.14 \\
\hline $\mathrm{h}^{31.7}$ & 1.03 & 1.23 & 1.60 & 1.62 & 1.55 \\
\hline$i^{31.7}$ & 0.35 & 1.73 & 1.77 & 1.78 & 0.59 \\
\hline $\mathrm{j}^{31.7}$ & 1.06 & 1.23 & 1.62 & 1.63 & 0.58 \\
\hline$c^{115.4}$ & 4.04 & 0.00 & 4.04 & 4.07 & 0.54 \\
\hline $\mathrm{d}^{115.4}$ & 0.56 & 0.42 & 0.70 & 0.70 & 0.36 \\
\hline $\mathrm{e}^{115.4}$ & 0.56 & 1.23 & 1.35 & 1.35 & 0.08 \\
\hline$f^{115.4}$ & 3.57 & 0.87 & 3.67 & 3.50 & 4.92 \\
\hline $\mathrm{g}^{115.4}$ & 0.79 & 1.73 & 1.90 & 1.93 & 1.47 \\
\hline $\mathrm{h}^{115.4}$ & 3.61 & 1.23 & 3.81 & 3.70 & 3.08 \\
\hline $\mathrm{i}^{115.4}$ & 1.23 & 1.73 & 2.13 & 2.18 & 2.59 \\
\hline $\mathrm{j}^{115.4}$ & 3.72 & 1.23 & 3.92 & 3.85 & 1.82 \\
\hline
\end{tabular}

Table 4. Summary of the ' $b_{r y}$ ' value calculated for the asymmetrical models from the proposed SBCM and comparison with the results from the SAM.

\begin{tabular}{|c|c|c|c|c|c|c|c|c|c|c|c|}
\hline Models & $b_{r y, s}$ & $e_{r y}$ & $e_{\text {accrry }}$ & $b_{r y, w}$ & $b_{r y, f}$ & $P_{x}$ & $\boldsymbol{b}_{r y, B, C M}$ & $b_{r y, B}$ & $\begin{array}{c}\boldsymbol{b}_{r y} \\
(\mathrm{SBCM})\end{array}$ & $\begin{array}{c}b_{r y} \\
(\mathrm{SAM})\end{array}$ & $\%$ Diff. \\
\hline $\mathrm{k}^{13.1}$ & 0.3 & 0.17 & 0.24 & 1.13 & 1.25 & 4.3 & 1.15 & 1.11 & 1.15 & 1.14 & 0.9 \\
\hline $1^{32.8}$ & 0.1 & 0.01 & 0.31 & 1.53 & 1.60 & 13 & 1.54 & 1.47 & 1.47 & 1.47 & 0 \\
\hline $\mathrm{m}^{96.8}$ & 0.15 & 0.28 & 0.32 & 1.55 & 1.28 & 0.1 & 1.31 & 1.22 & 1.23 & 1.25 & 1.6 \\
\hline
\end{tabular}

\subsection{Effect of the Disposition of the Lateral Load Resisting Elements in the Building Plan}

The disposition of the lateral load resisting elements in the building plan was found to be the major determiner of the ' $b_{r}$ ' value or torsional stiffness in the building. The torsional stiffness was found to be higher for buildings with walls or frames that are away from the CR. This effect was found in both symmetrical as well as asymmetrical building models. For low-rise and medium-rise buildings, the building with a single open wall at the center, for example, model 'a' was found to be torsionally flexible. Likewise, building with wall elements that are nearer to the edges (models ' $\mathrm{e}$ ', ' $\mathrm{g}$ ', and ' $\mathrm{i}$ ') were found to be torsionally stiffer compared with the buildings having the same wall configuration with additional walls near the CR of the building (models ' $\mathrm{f}$ ', ' $\mathrm{h}$ ', and ' $\mathrm{j}$ '), and buildings with all walls nearer to the CR (model 'd'). Similarly, building with wall elements aligned about both principle directions (models ' $\mathrm{g}$ ' to ' $j$ ') were found to be more torsionally stiffer compared to buildings with walls aligned in one direction only (models ' $\mathrm{d}$ ' to ' $\mathrm{f}$ '). Moreover, when the models with walls at the four corners (' $i$ ' and ' $j$ ') were compared with similar models with walls located at the middle of the building edges (' $\mathrm{g}$ ' and ' $\mathrm{h}$ '), the former models were found to have slightly higher torsional stiffness for the pure SW models and slightly lower torsional stiffness for the dual system compared to the latter models. As the latter models can also prevent lights and ventilations, models with corners walls are recommended. 
Furthermore, in buildings with pure shear walls, adding frames at the perimeter were found to increase the torsional stability, for example in model ' 1 '.

\subsection{Effect of Magnitude of Translational Stiffness (K)}

In a pure SW building with multiple walls, and a building with a dual system, the torsional rigidity of the building was not only found to be controlled by the disposition of the structural elements in the floor plan but also by the relative disposition of the lateral stiffness. For example, in model ' $h$ ', for the same disposition of walls and frames, the torsional stiffness of the building increased with the decrease in the lateral stiffness of the central core wall and vice versa. In model ' $h$ ', when the translational stiffness of the central core wall was doubled and the translational stiffness of other walls were kept unchanged, the ' $b r^{\prime}$ ' value decreased by about 1.4 times. For low-rise buildings (below 10 storey) consisting of central core walls (having ' $\mathrm{n}$ ' times higher translational stiffness compared to the stiffness of outer walls in the direction of motion considered) to be torsionally stable, the outer walls should be at least (in average) ' $r \sqrt{(1+n) /(1+m)}^{\prime}$ distance away from the $\mathrm{CR}$. Where ' $m$ ' is the ratio of the translational stiffness of the outer walls, for example: for $\mathrm{y}$-direction of motion $m=K_{x} / K_{y}$. If the ratios ' $\mathrm{m}$ ' and ' $\mathrm{n}$ ', member disposition, and shape of the walls are kept unchanged, the increase in stiffness will not affect ' $b_{r}$ ' value. In a dual system, the effect of translational stiffness depended on stiffness ratio $(P)$. The effect of the shape of the walls and the effect of flexural to shear stiffness ratio $(P)$ in the dual system are discussed further in Sections 3.2.1 and 3.2.2, respectively.

\subsubsection{Effect of Shape of the Wall}

The shape of the shear walls or core walls is found to influence the torsional stiffness in medium to high-rise buildings. As shear induced torsional stiffness of the closed shaped or semi-closed core walls (model ' $c$ ') are higher compared to open and rectangular or crossed walls (model ' $a$ '), the closed walls are found to considerably improve the torsional stiffness of the building. In medium to high-rise buildings, these walls can be placed near the center of the building, whereas in low-rise buildings such walls should be avoided near the center of the building.

\subsubsection{Effect of Flexural to Shear Stiffness Ratio (P) in Dual System}

The torsional stiffness of the dual system was found to be considerably influenced by the flexural to shear stiffness ratio $(P)$. In the dual buildings with a dominant SW system or higher value of ' $P$ ', higher torsional stiffness was observed when the elastic radius ratio due to the SW system $\left(b_{r, s}\right)$ is greater than the elastic radius ratio due to the MRF system $\left(b_{r, f}\right)$. Similarly, in buildings with a dominant MRF system or lower value of ' $P$ ', a higher torsional stiffness were observed when $b_{r, f}>b_{r, s}$.

\subsection{Effect of Building Height (H)}

The ' $b_{r}$ ' value increased considerably with the increase of the building height for pure shear wall buildings. For example, for model ' $c$ ', the ' $b_{r}$ ' value increased from 0.8 to 4.1 when building height was increased from $13.1 \mathrm{~m}$ to $115.4 \mathrm{~m}$. Similarly, in the dual system with $b_{r, s}<b_{r, f}$ ' $b_{r}$ ' value increased by a small amount and in pure MRF buildings the ' $b_{r}$ ' value remained unchanged when building height was increased. Moreover, in a building with a dual system consisting of $b_{r, s}>b_{r, f}{ }^{\prime}{ }^{\prime} b_{r}$ ' value slightly decreased with the increase of the building height. This atypical effect of building height on a different type of structural system was observed mainly due to each system having a different effective height (given in Table 1).

\subsection{Effect of the Aspect Ratio of the Floor Plan of the Building}

Aspect ratio is the ratio of the larger to the smaller dimension of the building about the two principal directions. To assess the effect of the aspect ratio (AR) of the floor plan of the building, the building models ' $a$ ' to ' $j$ ' were transformed into the rectangular building 
by increasing the length from 24.7 to $74.1 \mathrm{~m}$ and moving the position of the walls, while keeping the same configuration of the building model shown in Figure 4. As low-rise buildings are found to be comparatively torsionally unstable, $13.1 \mathrm{~m}$ height was selected for the comparison. The comparison of the ' $b_{r}$ ' values for the square $(\mathrm{AR}=1)$ and rectangular building models $(\mathrm{AR}=3)$ are shown in Figure 7.

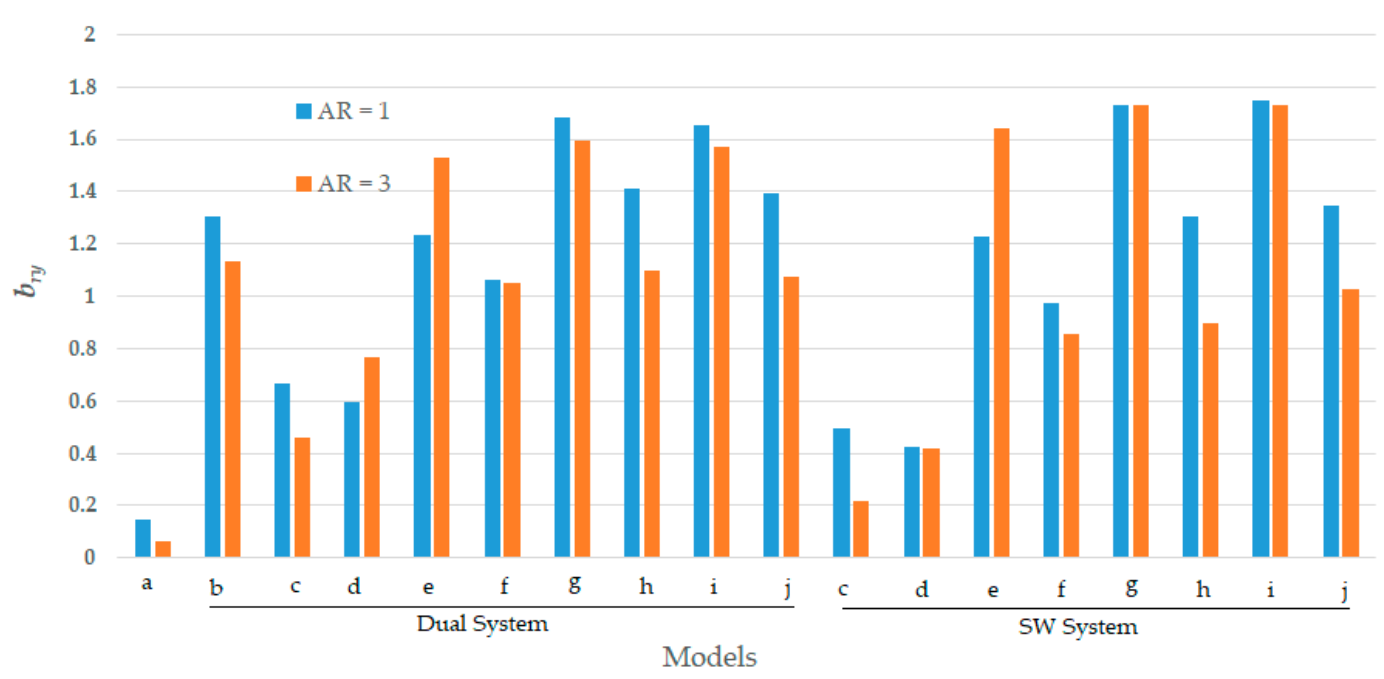

Figure 7. Comparison of the results of the elastic radius ratio ' $b_{r y}$ ' for the buildings with an aspect ratio (AR) of 1 and 3 , and a building height of $13.1 \mathrm{~m}$.

From the chart, it can be seen that the ' $b_{r}$ ' value for rectangular buildings only increased for the dual system model ' $d$ ', and for model ' $e$ '. This increase was mainly due to the higher increase ( 3 times) in the distance of the walls from CM compared to the increase in the radius of gyration (only increased by 2.23 times). For all other models, a reduction in ' $b_{r}$ ' values was obtained by increasing the aspect ratio. This is mainly because the distance from the $\mathrm{CM}$ to the wall aligned along the length of the building has remained the same, while the radius of gyration increased by 2.23 times. The highest reduction was obtained for models with central core walls (models ' $c$ ', ' $h$ ', ' $f$ ' and ' $j$ ') due to a relatively higher decrease in the bending torsional stiffness. Therefore, the placement of the core walls at the center of the low-rise rectangular building is more vulnerable compared to a square building with an equal floor area.

\subsection{Effect of Eccentricity (e) and Accidental Eccentricity $\left(e_{a c c}\right)$}

As eccentricity causes the coupling of the translational and torsional modes, torsional stiffness reduces with the increase of the eccentricity. In order to reduce torsion, the distance between CM and CR need to be reduced [30]. However, the eccentricity only caused the bending torsional stiffness to deteriorate, and it has no impact on the torsional stiffness due to shear. From Table 4, it is seen that the percentage decrease in ' $b_{r}{ }^{\prime}$ value due to eccentricity in building ' $\mathrm{k}$ ' (13.1 m height) having ' $e_{r y}$ ' of 0.17 is higher compared to building ' $\mathrm{m}$ ' (96.5 $\mathrm{m}$ height) having ' $e_{r y}$ ' value of 0.28 . This shows that, despite having a comparatively higher ' $e_{r y}$ ' value, building ' $m$ ' with higher building height had a higher ' $b_{r}$ ' value compared to building ' $k$ '. This is mainly because the torsional stiffness due to shear (which is independent of the eccentricity) increases with height, and it compensates for the decrease in ' $b_{r}$ ' value due to increased eccentricity. Similarly, the accidental eccentricity $\left(e_{a c c}\right)$ was found to have a similar effect as eccentricity $(e)$.

\section{Conclusions}

This study aims to introduce a fast, simple, and reliable manual calculation method (SBCM) for assessing the torsional stability of the multi-storey building under elastic 
conditions. The simple sets of equations derived in SBCM method are useful for buildings with a shear wall, a moment resisting frame, and a dual structural system consisting of horizontal as well as vertical stiffness irregularity. The proposed method determines the torsional stability by quantifying the elastic radius ratio of the building. The accuracy and robustness of the proposed method have been verified through the parametric study consisting of 81 different multi-storey building models. The proposed method predicted the elastic radius ratio of the building within the $5 \%$ difference to the static analysis method, a reputed computer analysis method. Based on the parametric study, the following conclusions can be drawn:

- The disposition of the lateral load resisting elements in the building plan was found to be the major determiner of the torsional stiffness of the building. The torsional stiffness is found to be higher for buildings with walls or frames that are located away from the center of rigidity. The highest elastic radius ratio was obtained for buildings with all walls at the building edges or corners. Moreover, a building with wall elements aligned about both principle directions was found to be more torsionally stiffer compared to a building with walls aligned in one direction only.

- The effect of the magnitude of translational stiffness on torsional stiffness was only found in pure shear wall (SW) building consisting of multiple walls, and in building with a dual structural system. In the pure SW system consisting central core wall along with other perimeter walls, the torsional stiffness significantly reduced when the translational stiffness of the central core wall was increased.

- In the dual system, the flexural to shear stiffness ratio was found to influence the torsional stiffness. The higher value of the stiffness ratio is beneficial in building having walls along the edges. On the contrary, a lower stiffness ratio was found to be beneficial for buildings with core walls positioned near the center of the building.

- Shear torsional stiffness was found to be dependent on the shape of the walls. For closed shaped or semi-closed core walls, the torsional stiffness was found to be higher compared to open and rectangular walls. The contribution of these walls were found to increase with the increase in building height.

- A rectangular building with central core walls were found to be more torsionally unstable compared to a square building having the same floor area.

- Reduction in torsional stiffness was found with the increase of both strength eccentricity and accidental eccentricity. However, their effects were found to reduce with the increase of building height.

The intention of this proposed method is to verify the dynamic analysis recommended by the Standards which is based on linear elastic behavior. The effects of non-linearity can be taken into account by the ductility reduction factor, but how asymmetry affects the factor is outside the scope of this study. Similarly, future research is recommended to assess the applicability of this method to other types of lateral loads such as wind load, and building with other structural materials such as steel and timber.

Author Contributions: Conceptualization, P.K. and E.L.; methodology, P.K. and E.L.; software, P.K.; validation, P.K.; formal analysis, P.K.; investigation, P.K.; resources, P.K. and E.L.; data curation, P.K.; writing—original draft preparation, P.K.; writing—review and editing, P.K. and E.L.; visualization, P.K.; supervision, E.L.; project administration, P.K. All authors have read and agreed to the published version of the manuscript.

Funding: This research received no external funding.

Institutional Review Board Statement: Not applicable.

Informed Consent Statement: Not applicable.

Conflicts of Interest: The authors declare no conflict of interest. 


\section{Appendix A. Derivation of Equation (12)}

Let's consider a pure SW building having a pair of shear wall. The lateral stiffness of the walls are ' $K_{x 1}$ ' and ' $K_{x 2}$ ' and their distance from the center of mass (CM) is ' $x_{1}$ ' and ' $x_{2}$ ', respectively as shown in Figure A1. The distance between the CM and center of rigidity $(C R)$ is equal to eccentricity ' $e_{y}$ '. By the definition of $C R$,

$$
e_{y}=\frac{\sum K_{x i} x_{i}}{\sum K_{x i}}=\frac{K_{x 1} x_{1}+K_{x 2} x_{2}}{K_{x 1}+K_{x 2}}
$$

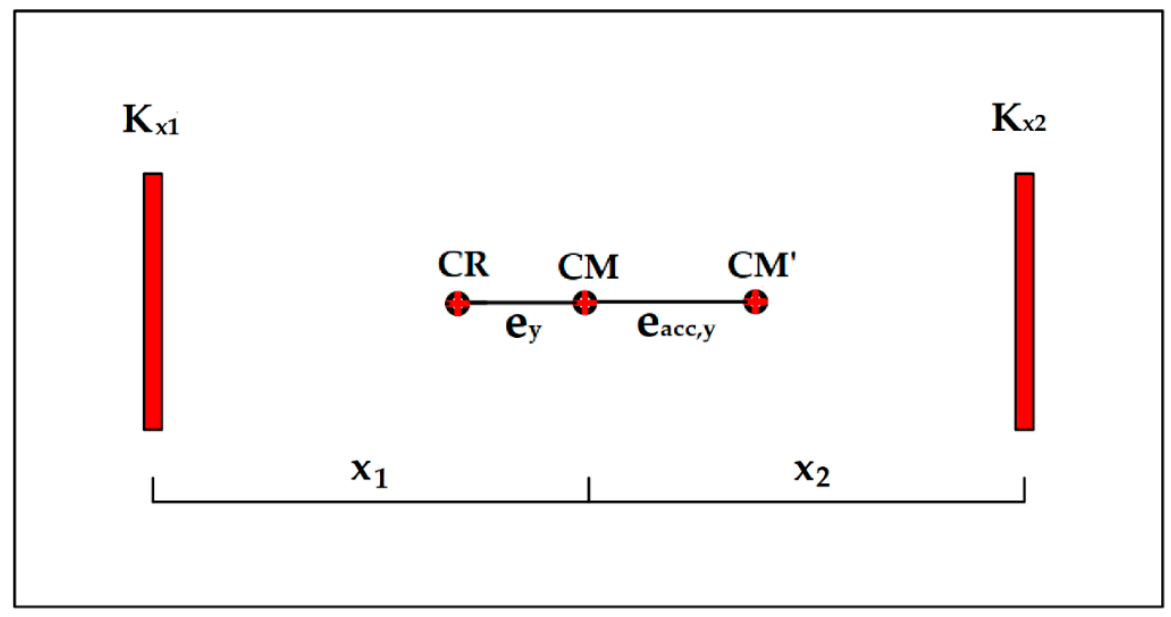

Figure A1. Pure SW building consisting of pairs of shear walls.

Similarly, for the y-direction of motion, the elastic torsional radius due to the bending mechanism with respect to the $\mathrm{CM}\left(b_{y, B, C M}\right)$ and $\mathrm{CR}\left(b_{y, B}\right)$ can be determined using Equations (A2) and (A3), respectively.

$$
\begin{gathered}
b_{y, B, C M}{ }^{2}=\frac{K_{x 1} x_{1}^{2}+K_{x 2} x_{2}{ }^{2}}{K_{x 1}+K_{x 2}} \\
b_{y, B}{ }^{2}=\frac{K_{x 1}\left(x_{1}-e_{y}\right)^{2}+K_{x 2}\left(x_{2}-e_{y}\right)^{2}}{K_{x 1}+K_{x 2}}
\end{gathered}
$$

Substituting Equation (A1) in Equation (A3) gives,

$$
b_{y, B}{ }^{2}=\frac{K_{x 1} x_{1}^{2}+K_{x 2} x_{2}^{2}}{K_{x 1}+K_{x 2}}-\frac{\left(K_{x 1}+K_{x 2}\right) e_{y}^{2}}{K_{x 1}+K_{x 2}}=b_{y, B, C M^{2}}-e_{y}^{2}
$$

The radius of gyration $(r)$ of the building floor plan (considering uniform mass distribution) about the CM is equal to the square root of polar moment of inertia $\left(I_{z}=I_{x}+I_{y}\right)$ divided by the floor area $(A)$ of the building.

$$
r=\sqrt{\frac{I_{x}+I_{y}}{A}}
$$


Similarly, the radius of gyration of the building about point $\mathrm{CM}^{\prime}$ (the position of $\mathrm{CM}$ shifted to account for the dynamic effect due to accidental eccentricity) can be determined using Equation (A6).

$$
r^{\prime}=\sqrt{\frac{\left(I_{x}+A e_{a c c, y^{2}}\right)+I_{y}}{A}}=\sqrt{r^{2}+e_{a c c, y^{2}}}=r \sqrt{1+\frac{e_{a c c, y^{2}}}{r^{2}}}=r \sqrt{1+e_{a c c, r y}{ }^{2}}
$$

The elastic radius ratio about the $\mathrm{CR}$ of the building due to the bending mechanism considering the accidental eccentricity can be determined by dividing Equation (A4) by Equation (A6),

$$
b_{r y, B}=\sqrt{\frac{b_{y, B^{2}}}{r^{\prime 2}}}=\sqrt{\frac{b_{y, B, C M^{2}-e_{y}^{2}}}{r^{2}\left(1+e_{a c c, r y}{ }^{2}\right)}}=\sqrt{\frac{b_{r y, B, C M^{2}-e_{r y}{ }^{2}}}{1+e_{a c c, r y}{ }^{2}}}
$$

\section{Appendix B. Example Calculation of the Elastic Radius Ratio for Building Models ' $\mathrm{g}$ ' and ' $k$ '}

Table A1. Calculation of the Elastic Radius Ratio for Building Model ' $\mathrm{g}$ '.

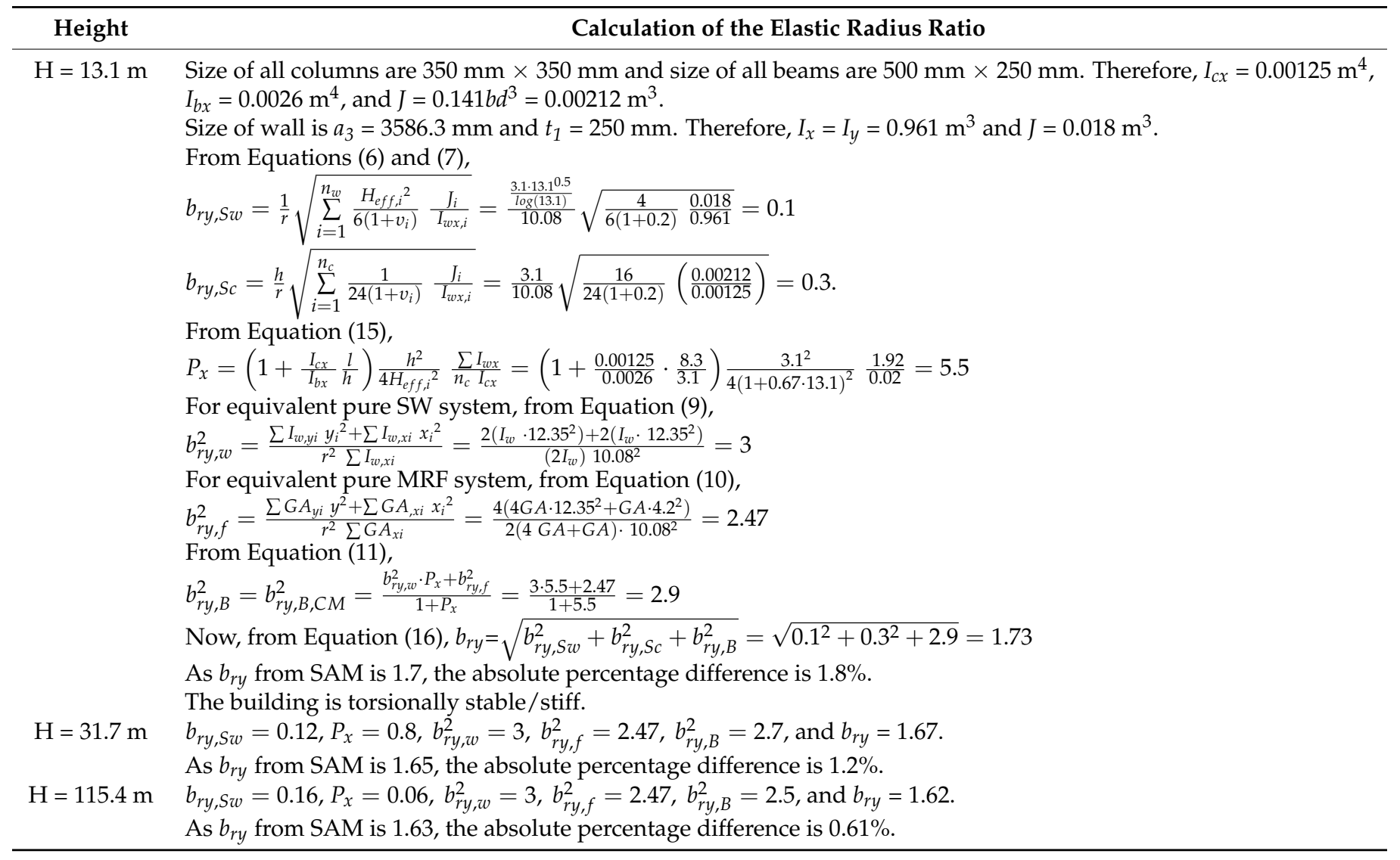


Table A2. Calculation of the Elastic Radius Ratio for Building Model ' $k$ '.

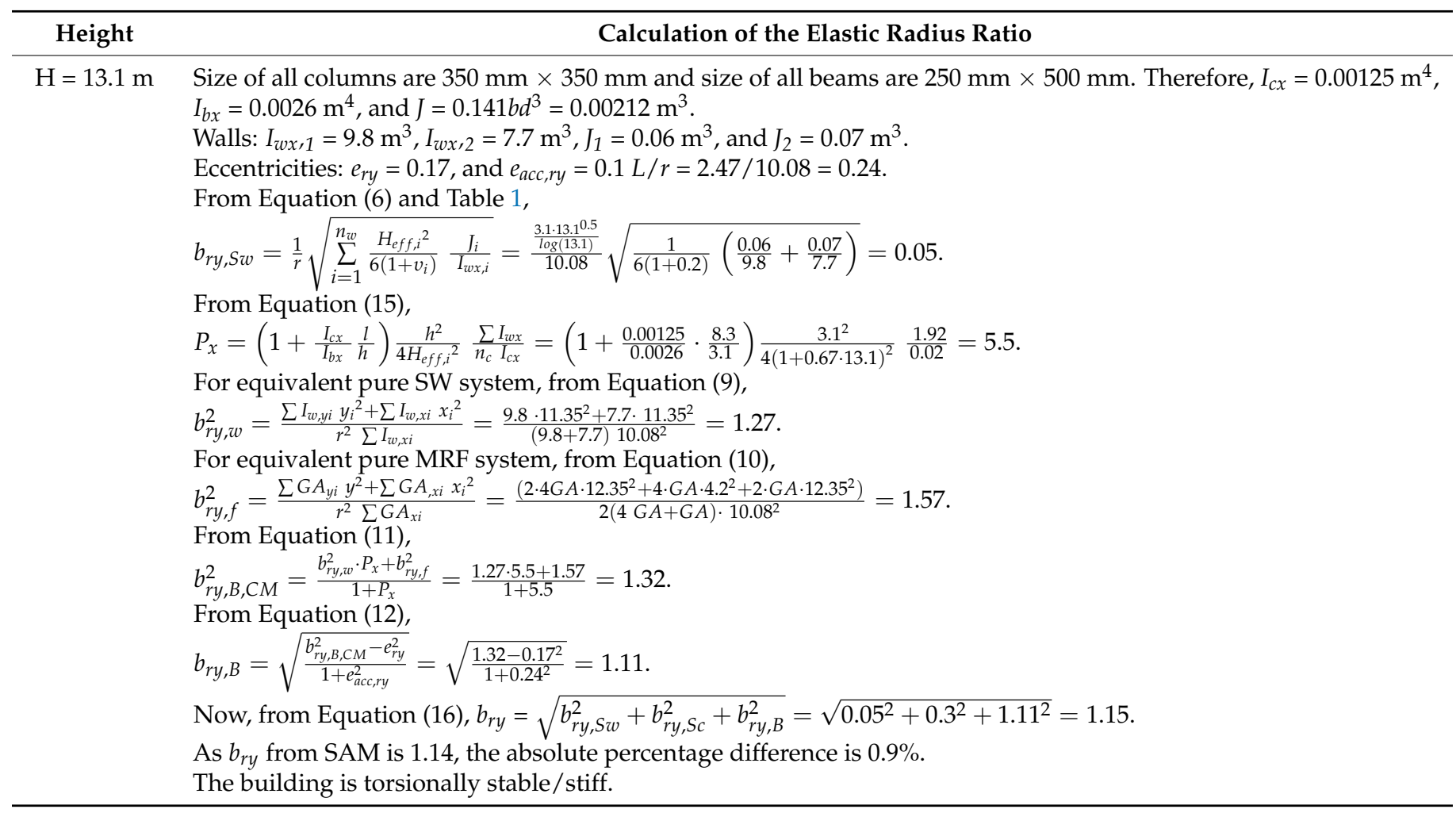

\section{References}

1. Lam, N.T.; Wilson, J.L.; Hutchinson, G.L. Review of the torsional coupling of asymmetrical wall-frame buildings. Eng. Struct. 1997, 19, 233-246.

2. Chitty, L. On the cantilever composed of a number of parallel beams interconnected by cross bars. Philos. Mag. Lond. Ser. 1947, 7, 685-699. [CrossRef]

3. Csonka, P. Procedure for rectangular sway frames (in Hungarian). In Mérnöki Továbbképz Intézet. Épitészet; Tudományos Könyvkiadó Vállalat: Budapest, Hungary, 1950.

4. Beck, H. Ein neues Berechnungsverfahren für gegliederte Scheiben, dargestellt am Beispiel des Vierendelträgers. Der Bauing. 1956, 31, 436-443.

5. Miranda, E. Approximate lateral deformation demands in multistory buildings. J. Struct. Eng. 1999, 125, 417-425. [CrossRef]

6. Blume, J.A. Dynamic characteristics of multi-story buildings. J. Struct. Div. 1968, 94, 337-402. [CrossRef]

7. Tso, W.K.; Zhu, T.J. Design of torsionally unbalanced structural systems based on code provisions I: Ductility demand. Earthq. Eng. Struct. Dyn. 1992, 21, 609-627. [CrossRef]

8. Chandler, A.M.; Duan, X.N. Performance of asymmetric code-designed buildings for serviceability and ultimate limit states. Earthq. Eng. Struct. Dyn. 1997, 26, 717-735. [CrossRef]

9. Gasparini, G.; Silvestri, S.; Trombetti, T. A simple code-like formula for estimating the torsional effects on structures subjected to earthquake ground motion excitation. In Proceedings of the 14th World Conference on Earthquake Engineering, Beijing, China, 12-17 October 2008.

10. Trombetti, T.; Palermo, M.; Silvestri, S.; Gasparini, G. Period shifting effect on the corner displacement magnification of onestorey asymmetric systems. In Proceedings of the 15th World Conference on Earthquake Engineering, Lisbon, Portugal, 24-28 September 2012.

11. Lumantarna, E.; Lam, N.; Wilson, J. Displacement-Controlled Behavior of Asymmetrical Single-Story Building Models. J. Earthq. Eng. 2013, 17, 902-917. [CrossRef]

12. Kan, C.L.; Chopra, A.K. Elastic earthquake analysis of a class of torsionally coupled buildings. J. Struct. Div. 1977, 103, 821-838. [CrossRef]

13. Rutenberg, A.; Hsu, T.I.; Tso, W.K. Response spectrum techniques for asymmetric buildings. Earthq. Eng. Struct. Dyn. 1978, 6, 427-435. [CrossRef]

14. Harasimowicz, A.P.; Goel, R.K. Seismic code analysis of multi-storey asymmetric buildings. Earthq. Eng. Struct. Dyn. 1998, 27, 173-185. [CrossRef]

15. Lin, J.L.; Tsai, K.C. Simplified seismic analysis of asymmetric building systems. Earthq. Eng. Struct. Dyn. 2007, 36, 459-479. [CrossRef] 
16. Khatiwada, P.; Lumantarna, E.; Lam, N.; Looi, D. Fast Checking of Drift Demand in Multi-Storey Buildings with Asymmetry. Buildings 2021, 11, 13. [CrossRef]

17. Lam, N.; Wilson, J.; Lumantarna, E. Effects of Building Asymmetry in Areas of Low-to-Moderate Seismicity. In Proceedings of the 2015 World Congress on Advances in Structural Engineering and Mechanics, Incheon, Korea, 25-29 August 2015; pp. $25-29$.

18. Dimova, S.L.; Alashki, I. Seismic design of symmetric structures for accidental torsion. Bull. Earthq. Eng. 2003, 1, 303-320. [CrossRef]

19. De la Llera, J.C.; Chopra, A.K. Estimation of Accidental Torsion Effects for Seismic Design of Buildings. J. Struct. Eng. 1995, 121, 102-114. [CrossRef]

20. Wang, Y.; Arnaouti, C.; Guo, S. A simple approximate formulation for the first two frequencies of asymmetric wall-frame multi-storey building structures. J. Sound Vib. 2000, 236, 141-160.

21. Mohamed, O.A.; Mehana, M.S. Assessment of Accidental Torsion in Building Structures Using Static and Dynamic Analysis Procedures. Appl. Sci. 2020, 10, 5509. [CrossRef]

22. Lumantarna, E.; Menegon, S.J.; Lam, N.; Wilson, J. Simplified approach for multi-storey asymmetrical buildings in regions of low to moderate seismicity. In Proceedings of the Australasian Structural Engineering Conference, Melbourne, Australia, 11-13 November 2020. accepted.

23. Tso, W.K.; Moghadam, A.S. Application of Eurocode 8 torsional provisions to multi-storey buildings. In Proceedings of the 11th European Conference on Earthquake Engineering, Paris, France, 6-11 September 1998.

24. Anastassiadis, K.; Athanatopoulou, A.; Makarios, T. Equivalent static eccentricities in the simplified methods of seismic analysis of buildings. Earthq. Spectra 1998, 14, 1-34. [CrossRef]

25. Makarios, T. Practical calculation of the torsional stiffness radius of multistorey tall buildings. Struct. Des. Tall Spec. Build. 2008, 17, 39-65. [CrossRef]

26. Khatiwada, P. Determination of center of mass and radius of gyration of irregular buildings and its application in torsional analysis. Int. Res. J. Eng. Technol. 2020, 7, 1-7.

27. Menegon, S.J.; Tsang, H.H.; Lumantarna, E.; Lam, N.T.K.; Wilson, J.L.; Gad, E.F. Framework for seismic vulnerability assessment of reinforced concrete buildings in Australia. Aust. J. Struct. Eng. 2019, 20, 143-158. [CrossRef]

28. Gass, S. SPACE GASS 12.85; ITS: Victoria, Australia, 2020.

29. Standards Australia. AS 1170.4-2007. In Structural Design Actions, Part 4: Earthquake Actions in Australia; Standards Australia: Sydney, Australia, 2007.

30. Botis, M.F.; Cerbu, C. A Method for Reducing of the Overall Torsion for Reinforced Concrete Multi-Storey Irregular Structures. Appl. Sci. 2020, 10, 5555. [CrossRef] 